find, a universal mechanism for the seasonal photoperiodic clock. This may be so, but it is difficult at the moment to equate data such as those of Lees-for the photoperiodic control of polymorphism in the aphid Megoura -with a circadian hypothesis. It is just possible that there are two or more mechanisms for the measurement of the critical day length (or night length), and the similarities between them are merely attributable to the fact that all organisms have evolved in an environment with a $24 \mathrm{~h}$ periodicity of light and dark.

The entrainment of circadian rhythms and the induction of diapause by thermoperiods are discussed in the fourth and seventh chapters, but the subject of temperature "shocks" is ignored. Chilling for short periods in the light or the dark, especially, is known to cause significant reversals of photoperiodic effect in plants and insects, and is also known to cause phase perturbation of circadian rhythms.

In the preface the author states that the presentation has been adopted so that the volume might be a useful reference for the student as well as the specialist. In my opinion this has been accomplished, and the book forms a welcome addition to the literature on photoperiodism.

D. S. SAUNDERS

\section{HISTORY OF SALMON}

\section{The Atlantic Salmon}

A Vanishing Species? By Anthony Netboy. Pp. $457+$ 24 plates. (London : Faber and F'aber, Ltd., 1968.) 70s. net.

THIs book is a history of the salmon populations of the countries bordering the North Atlantic Ocean. It is written for the general public and, in spite of a few misprints and inaccuracies, it is a scholarly account which should be of great value to all interested in the rational exploitation of natural resources.

Twelve chapters form the bulk of the book and each is a detailed account of events in one country (except for two chapters on England and Wales together). After a general introduction to the country and a description of its salmon rivers, there is an account of the changes in the salmon populations together with probable causes. The chapters end with reviews of the present situation and prognoses for the future. Mr Netboy begins his survey with Spain and works north along the European coast, then from Norway to the British Isles and thence to USA and Canada, and finally to Greenland and Iceland.

This treatment emphasizes the similarity of events in different countries. Early records show a great abundance of salmon in all suitable rivers and these were exploited only to a limited extent by the local people for their own use. The industrial revolution followed different patterns in different countries but always with deleterious effects on salmon stocks from one or more of the following causes - damming of rivers to give water power; deforestation leading to silting of spawning grounds; water pollution killing young and old fish. With improved transport, salmon were despatched to distant markets and overfishing also became a problem. Thus salmon, once abundant, became first rare and then non-existent in many rivers. A new threat since 1960 has been the fishing for salmon in the sea off Greenland and elsewhere.

The clash between industry and fisheries was generally won by industry, although anti-pollution laws existed in Ireland in 1466 and the importance of allowing some free passage upstream was recognized in Magna Carta. When salmon angling developed as a sport, there appeared a powerful new pressure group working for preservation and reinstatement of salmon rivers. The dangers to stocks during their freshwater life are now widely appre. ciated and research has led to interesting developments such as large-scale artificial smolt-rearing in Sweden.

The book includes 24 tables, many maps and diagrams, many interesting photographs, a bibliography of 17 pages and an index. Mr Netboy has travelled widely and has consulted the principal experts of many countries. He has brought together an impressive array of statistics and historical evidence. He sums up the story so far: "civilization and salmon do not mix well unless extraordinary precautions are taken to protect their habitat". We must hope that modern civilization is sufficiently enlightened for this excellent food fish to continue to survive.

M. E. VARLEY

\section{BUTTERFLY BLUES}

\section{The Complete British Butterflies in Colour}

Illustrations by E. Mansell. Text by L. Hugh Newman. Pp. 144 (62 plates). (London: Ebury Press and Michael Joseph, 1968.) 35s.

The blurb's claim that this book is "beautiful and meticulously illustrated" ranks as hyperbole rather than untruth; the further assertion that the text is "informative" can happily be described as pleonastic. This is primarily a picture book which illustrates the butterflies native and immigrant to the British Isles. Each species is given a full page plate, showing its immature and adult forms, and the foodplant; the natural history is briefly described on the facing page.

The illustrations are certainly attractive, but they are not entirely faithful to their originals. The matt paper has robbed them of much of their brightness, as may be seen by comparing the dustjacket illustration to that in the text. The colours are too drab, and many are inaccurate in hue as well as in intensity. The Fritillaries and the Blues are the most serious casualties; the Adonis Blue, for example, has in nature a startling azure iridescence, admittedly difficult to capture in print, of which the blotched subfusc offered here is but a travesty. Nor have the subtle browns of the Skippers and Hairstreaks been accurately reproduced.

It would be unjust, however, to expect complete tonal accuracy in a book the price of which is as modest as is this one. Some of the butterflies are drawn larger than the natural size they are stated to be, and in several plates the printer has aligned the female sex symbol according to his whim instead of to the vertical. These are but minor blemishes in illustrations which are otherwise well composed and well executed.

The introduction describes the natural history of butterflies eloquently but briefly. No discussion is given on the remarkable migratory habits of butterflies, which in two species at least have recently been shown to be governed by sensitivity to Sun orientation and photoperiod $^{1}$. Nor is any mention made of pheromones, the importance of which in insect behaviour has become increasingly obvious.

NICHOLAS WADE

${ }^{2}$ Baker, R. R., Phil. Trans. Roy. Soc., B, 253, 309 (1968).

\section{OBITUARIES}

\section{Professor J. W. Munro}

James Watson Munro, Emeritus Professor of Zoology and Applied Entomology, London (Imperiail College), died at the age of 79 on March 13. He had made a fundamental contribution to the developmeni of entomology in Britain, not least in persuading the Univer- 